\title{
PENGARUH LIMBAH SERAT KULIT PINANG TERHADAP SERAPAN AIR DAN KUAT TEKAN PADA PAVING BLOCK
}

\author{
Muliadi $^{1)}$, Wesli' ${ }^{2)}$, Aulia Rahman ${ }^{3)}$ \\ Jurusan Teknik Sipil, Fakultas Teknik, Universitas Malikussaleh

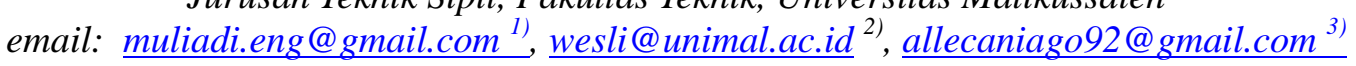

DOI: http://dx.doi.org/10.29103/tj.v10i1.252

(Received: August 2019 / Revised: October 2019 / Accepted: February 2020)

\begin{abstract}
Abstrak
Paving block merupakan komposisi bahan bangunan yang dibuat dari paduan semen atau bahan perekat hidrolis, air, dan agregat halus dengan atau tanpa bahan tambahan lainya. Penambahan bahan lainya bisa berupa limbah alami atau limbah kimia dalam material paving block. Dalam penelitian ini dilakukan penambahan limbah alami (serat pinang) dalam material paving block. Tujuan penelitian ini adalah untuk mengetahui pengaruh penambahan serat kulit pinang terhadap serapan air dan kuat tekan pada paving block. Metode penambahan serat kulit pinang dilakukan dengan cara subsitusi dari volume pasir, dengan panjang serat 1-3 cm, perbandingan komposisi 1Pc : 3Ps, faktor air semen 0.35, klasifikasi mutu rencana mutu D. Variasi campuran serat yang digunakan adalah $0 \%, 5 \%, 10 \%, 15 \%$, dan $20 \%$, dengan cetakan berukuran $8 \times 8 \times 11,6 \mathrm{~cm}$ dan slinder $15 \times 30 \mathrm{~cm}$, masing-masing varian memiliki 5 sampel. Pengujian dilakukan pada sampel berumur 28 hari, dengan hasil rata-rata serapan air variasi $0 \%$ sebesar $9,57 \%$, rata-rata serapan air variasi $5 \%$ sebesar $15,17 \%$, rata-rata serapan air variasi $10 \%$ sebesar $15,56 \%$, rata-rata serapan air variasi $15 \%$ sebesar $15,96 \%$, rata-rata serapan air variasi $20 \%$ sebesar $16,65 \%$. Nilai rata-rata kuat tekan variasi $0 \%$ sebesar 8,83 MPa, rata-rata kuat tekan variasi $5 \%$ sebesar 7,44 MPa, rata-rata kuat tekan variasi $10 \%$ sebesar $6,23 \mathrm{MPa}$, rata-rata kuat tekan variasi $15 \%$ sebesar 5,13 MPa, rata-rata kuat tekan variasi $20 \%$ sebesar 4,20 MPa. Dari hasil pengujian menggambarkan bahwa, pengaruh pemanfaatan serat kulit pinang pada pembuatan paving block meningkatnya nilai serapan air dan menurunnya nilai kuat tekan.
\end{abstract}

Kata kunci: paving block, serapan air, kuat tekan.

\begin{abstract}
Paving blocks are a composition of building materials made from a mixture of cement or hydraulic adhesive, air, and fine aggregates with or without other additives. The addition of other materials can be either natural waste or chemical waste in material paving blocks. In this study testing of natural waste (areca fiber) was tested in paving blocks. The purpose of this study was to study the effect of areca fiber on air absorption and compressive strength on paving blocks. The method of choosing areca fiber is substituted from the volume of sand, with fiber lengths of 1-3 cm, allocating a composition of $1 \mathrm{Pc}: 3 \mathrm{Ps}$, cement water factor 0.35 , calcification of supplier quality suppliers D. Variation of mixed fiber used is $0 \%, 5 \%, 10 \%, 15 \%$, and $20 \%$, with prints having $8 \times 8 \times 11.6 \mathrm{~cm}$ and $15 \times 30 \mathrm{~cm}$ slinders, each variant has 5 samples. Tests were carried out on a 28 day trial sample. With variations in the average air absorption variation of $0 \%$ by $9.57 \%$, the average air absorption variation of $5 \%$ by $15.17 \%$, the average air absorption variation of $10 \%$ by $15.56 \%$, the average variation of air absorption $15 \%$ by $15.96 \%$, air absorption average variation of $20 \%$ by $16.65 \%$. The average value of compressive strength is $0 \%$ variation of $8.83 \mathrm{MPa}$, the average compressive strength of $5 \%$ variation is $7.44 \mathrm{MPa}$, the average compressive strength
\end{abstract}


of variation is $10 \%$ by $6.23 \mathrm{MPa}$, the average compressive strength variation is $15 \%$ of $5.13 \mathrm{MPa}$, the average compressive strength of variation of $20 \%$ is $4.20 \mathrm{MPa}$. From the evaluation results, evaluation, utilization of areca fiber in the manufacture of paving blocks, added value, air uptake, and decreasing the value of compressive strength.

Keywords: paving block, water uptake, compressive strength.

\section{Latar Belakang}

Menurut Wintoko (2012), paving block adalah bata beton yang memiliki variasi bentuk dan warna, dan dapat dipergunakan untuk pengerasan permukaan tanah. Secara teknis paving block merupakan gabungan dari sebuah komposisi mortar konstruksi yang terdiri dari semen atau zat perkerasan lainya, agregat halus, dan air. Penelitian pembuatan paving block dilakukan dengan mensubsitusikan serat kulit pinang terhadap volume padat pasir, yang dimaksud subsitusi disini adalah, dengan mengurangi jumlah volume pasir yang digunakan sebagai bahan campuran pembuatan paving block, dan ditambah dengan volume serat pinang sebagai pengganti pasir yang dikurangi. Menurut Fauna Adibroto (2014), Paving block banyak digunakan dalam bidang konstruksi dan merupakan salah satu alternatif pilihan untuk lapis perkerasan permukaan tanah. Kemudahan dalam pemasangan, perawatan yang relatif murah serta memenuhi aspek keindahan mengakibatkan paving block lebih banyak disukai.

Serat kulit pinang adalah serat alami yang banyak tersedia bahan bakunya di daerah lokal, penggunaan serat ini diharapkan dapat memperbaiki daya serapan air, kuat tekan pada paving block, sehingga dapat digunakan paving block yang lebih tipis dan ekonomis, disamping itu penggunaan serat kulit pinang dilakukan untuk mencegah pencemaran terhadap lingkungan dari limbah kulit pinang itu sendiri. Menurut Danu Saputro (2007), jika limbah dibuang terus-menerus tanpa adanya pengelolaan yang maksimum, hal tersebut dapat menimbulkan gangguan keseimbangan, dengan demikaian menyebabkan lingkungan tidak berfungsi seperti semula dalam arti kesehatan, kesejahteraan, dan keselamatan hayati.

\section{Metode Penelitian}

\subsection{Tahapan Pelaksanaan}

Penelitiaan ini dimulai dari studi literatur, persiapan dan pengadaan material. Selanjutnya dilakukan pemeriksaan sifat-sifat fisis agregat, perencanaan mix design, pencetakan, perawatan, pengujian dan dilanjutkan dengan pengolahan data hasil penelitian. Perencanaan pencampuran serat kulit pinang pada paving block sebagai subsitusi agregat halus adalah $(0 \%, 5 \%, 10 \%, 15 \%$, dan $20 \%)$ dari volume pasir, paving block dicetak dalam cetakan berbentuk kubus ukuran $8 \times 8 \times$ $11,6 \mathrm{~cm}$. Bahan-bahan penyusun paving block antara lain, semen, pasir, serat kulit pinang, dan air. Setelah proses pencetakan dilakukan maka sampel dilakukan pendiaman selama 24 jam, kemudian dilakukan perawatan terhadap sampel dengan cara perendaman air selama 28 hari, setelah melakukan perawatan benda uji atau sampel dikeluarkan dari perendaman dan dikeringkan dengan cara dilap, sehingga sampel mengalami kering permukaan lalu dilanjutkan dengan pengujian terhadap serapan air dan pengujian kuat tekan. Setelah pengujian terhadap sampel selesai selanjutnya dilakukan pengolahan terhadap data yang diperoleh dan mengambil kesimpulan dari hasil penelitian yang telah dilakukan. 


\subsection{Pengolahan Serat Kulit Pinang}

Pengolahan serat kulit pinang dilakukan dengan cara kulit pinang dibersihkan dan dijemur, selanjutnya kulit pinang di buat menjadi serat dengan menggunakan alat bantu benda tajam (pisau atau parang), kemudian dipotongpotong dengan jarak $1-3 \mathrm{~cm}$ (potongan acak). Serat pinang yang telah dipotong lalu ditimbang untuk dicampur dengan dengan variasi $0 \%, 5 \%, 10 \%, 15 \%$, dan $20 \%$ dari volume pasir. Bentuk serat kulit pinang seperti diperlihatkan Gambar 1.

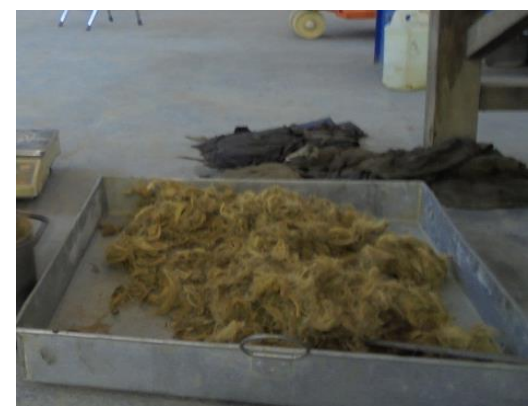

Gambar 1 Serat kulit pinang

\subsection{Pengujian Sifat Fisis Material}

\subsubsection{Berat jenis dan volume padat semen}

Berat jenis semen adalah perbandingan antara berat volume kering semen pada suhu kamar dengan berat volume air suling. Adapun langkah pengujian ini dengan menggunakan botol Le Chatelier, minyak tanah dimasukkan ke dalam botol dengan sekala antara $0-1 \mathrm{~cm}$, kemudian botol didiaman dalam rendaman air hingga suhu botol sama dengan suhu air tempat perendaman, selanjutnya botol dikeluarkan dan masukkan semen yang sudah ditimbang sebanyak 64 gr, sebanyak tiga sampel, setelah itu botol dimasukkan lagi dalam perendaman air hingga minyak tanah jernih.

Pengujian ini dilakukan untuk mengetahui volume padat pada semen dan juga digunakan sebagai perencanaan untuk pencampuran (mix design). Pada tabung slinder dilkukan pengitungan volume dengan cara memasukan air dan ditutup dengan plat kaca sehingga air di dalam tabung tidak terdapat gelembung udara, kemudian timbang berat plat slinder, air dan kaca secara bersamaan. selanjutnya semen dimasukkan kedalam slinder dengan melakukan tiga kali tumbukan secara berlapis, masing-masing tumbukan dilakukan sebanyak 25 kali tumbukan. Kemudian slinder di timbang.

\subsubsection{Berat jenis dan penyerapan air agregat halus}

Tujuan pengujian ini untuk memperoleh angka berat jenis curah, berat jenis kering permukaan, berat jenis semu, dan kemampuan menyerap air agregat halus.

\subsubsection{Analisa saringan agregat halus}

Menurut ASTM C 33-1982, pengujian ini berguna untuk mengetahui ukuran dan gradasi butiran agregat halus dari yang kecil sampai terbesar menggunakan saringan untuk keperluan perencanaan campuran (mix design) paving block. Pengujian ini dilakukan dengan cara melakukan pengayakan terlebih dahulu dengan saringan No.4 dengan mengambil sampel sebanyak $5 \mathrm{~kg}$ yang lolos saringan. Setelah pengayakan benda uji dimasukan kedalam oven dengan suhu 
$(110 \pm 5)^{\circ} \mathrm{C}$ sampai berat tetap, selanjutnya dinginkan benda uji dengan diskalator selam 1 - 3 jam, timbang benda uji lalu benda uji diayak selam 15 menit dan berat sampel yang tertinggal di ayakan di hitung.

\subsubsection{Pengujian kadar kelembaban agregat halus}

Penelitian ini bertujuan untuk menentukan kelembaban (moisture content) yang terkandung didalam agregat halus. Pengujian dimulai dengan melakukan ayakan pasir yang lolos saringan No.4 sebanyak $5 \mathrm{~kg}$ yang lolos. Lalu dimasukkan ke dalam cawan dengan terlebih dahulu ditimbang berat cawannya, lalu pasir dimasukkan kedalam oven dengan suhu $) 100 \pm 5^{\circ} \mathrm{C}$ hingga berat tetap. Setelah kering timbng pasir berserta talam.

\subsubsection{Pemeriksaan berat volume gembur dan padat agregat halus}

Berat volume dibagi menjadi dua keaadaan yaitu berat volume gembur dan berat volume padat. Berat volume gembur merupakan perbandingan berat agregat dengan volume literan, sedangkan berat volume padat adalah perbandingan berat agregat dalam keadaan padat dengan volume literan. Bentuk pengujian berat volume gembur dapat diperlihatkan seperti pada Gambar 2.

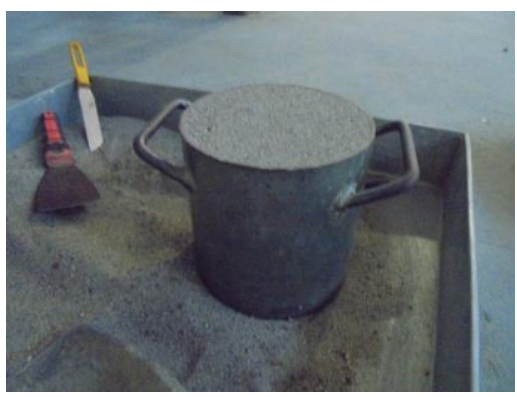

Gambar 2 Pengujian berat volume gembur

Pengujian seperti pada Gambar 2 dimaksudkan untuk menentukan berat isi agregat halus dan kasar yang didefinisikan sebagai perbandingan antara berat material kering dengan volume.

Untuk memperoleh data maka dilakukan penelitian dengan cara, menghitung volume silinder, perhitungan dilakukan dengan langkah berikut:

1) Timbang plat kaca

2) Timbang berat slinder

3) Isi air dengan air penuh

4) Tutup slinder dengan plat kaca sehingga tidak ada gelembung udara di dalam tabung

5) Hitung volume

Selanjutnya dilakukan pehitungan terhadap berat volume dengan langkah sebagai berikut:

1) Benda uji dikeringkan dengan menggunakan oven dengan suhu $(110 \pm 5)^{\circ} \mathrm{C}$

2) Lalu didinginkan didalam diskalator selama 1 - 3 jam

3) Untuk pengujian berat volume padat, masukkan benda uji kedalam selinder dalam 3 lapis dengan tiap lapisnya ditumbuk sebanyak 25 kali dengan menggunakan alat tumbuk 
4) Untuk pengujian berat volume padat, benda uji dimasukan didalam silinder tanpa melakukan pemadatan, lalu permukaanya diratakan.

5) Lalu timbang silinder berserta benda uji didalamnya.

\subsection{Campuran Paving Block (Mix Design)}

Menurut SNI 03-0691-1996, paving block adalah komposisi bahan bangunan yang dibuat dari campuran semen portland atau bahan perekat hidrolis sejenisnya, air, dan agregat halus dengan atau tanpa bahan tambahan lainya yang tidak mengurangi mutu bata beton itu. Sementara menurut SK SNI T-04-1990-F, blok beton adalah segmen-segmen kecil yang terbuat dari beton, dengan bentuk segi empat atau segi banyak yang dipasang sedemikian sehingga saling mengunci, bidang atas blok beton terkunci harus diberi pinggul. Berdasarkan SNI 03-06911996, paving block memiliki beragam mutu dan klasifikasi seperti pada Tabel 1.

Tabel 1 Mutu paving block (SNI 03-0691-1996)

\begin{tabular}{cccccc}
\hline \hline \multirow{2}{*}{ Mutu } & \multicolumn{2}{c}{$\begin{array}{c}\text { Kuat Tekan } \\
\text { (Mpa) }\end{array}$} & \multicolumn{2}{c}{$\begin{array}{c}\text { Kuat Aus } \\
(\mathbf{m m} / \mathbf{m e n i t})\end{array}$} & $\begin{array}{c}\text { Penyerapan Air } \\
(\boldsymbol{\%})\end{array}$ \\
\cline { 2 - 6 } & rata-rata & Min & rata-rata & Min & rata-rata maks \\
\hline \hline A & 40 & 35 & 0,09 & 0,103 & 3 \\
\hline B & 20 & 17 & 0,13 & 0,149 & 6 \\
\hline C & 15 & 12,5 & 0,16 & 0,184 & 8 \\
\hline $\mathrm{D}$ & 10 & 8,5 & 0,219 & 0,251 & 10 \\
\hline \hline
\end{tabular}

Penggunaan paving block harus sesuai dengan mutu yang dibutuhkan untuk diaplikasikan, diantaranya:

1. Mutu A : Untuk Jalan

2. Mutu B : Untuk Pelataran Parkir

3. Mutu C : Untuk Pejalan Kaki

4. Mutu D : Untuk Taman dan Penggunaan Lainya

Tabel 2 Proporsi campuran paving block

\begin{tabular}{|c|c|c|c|c|}
\hline \multirow{3}{*}{ No } & \multirow{3}{*}{$\begin{array}{c}\text { Klasifikasi } \\
\text { Paving block }\end{array}$} & \multirow{2}{*}{$\begin{array}{c}\text { Variasi } \\
\text { Campuran Serat } \\
\text { Kulit Pinang }\end{array}$} & \multicolumn{2}{|c|}{ Jumlah Sampel } \\
\hline & & & $\begin{array}{c}\text { Pengujian } \\
\text { Serapan Air }\end{array}$ & $\begin{array}{l}\text { Pengujian } \\
\text { Kuat Tekan }\end{array}$ \\
\hline & & $(\%)$ & $(S A)$ & $(K T)$ \\
\hline 1 & $\mathrm{Na}, \mathrm{Nb}, \mathrm{Nc}, \mathrm{Nd}, \mathrm{Ne}$ & 0 & 5 & 5 \\
\hline 2 & $1 a, 1 b, 1 c, 1 d, 1 e$ & 5 & 5 & 5 \\
\hline 3 & $2 a, 2 b, 2 c, 2 d, 2 e$ & 10 & 5 & 5 \\
\hline 4 & $3 a, 3 b, 3 c, 3 d, 3 e$ & 15 & 5 & 5 \\
\hline 5 & $4 a, 4 b, 4 c, 4 d, 4 e$ & 20 & 5 & 5 \\
\hline \multicolumn{3}{|c|}{ TOTAL } & 25 & 25 \\
\hline
\end{tabular}

Menurut Tri Mulyono (2004), proporsi bahan campuran ini ditentukan melalui perancangan beton ( mix design). Hal ini dimaksudkan agar proporsi dari campuran dapat memenuhi syarat kekuatan serta dapat memenuhi aspek 
ekonomis. Proporsi campuran dilakukan untuk mengetahui banyaknya material yang akan digunakan dalam campuran paving block. Proporsi campuran paving block seperti diperlihatkan pada Tabel 2.

\subsection{Pembuatan Paving Block}

Pembuatan paving block yang direncanakan adalah sebanyak 50 sampel, di mana masing-masing variasi campuran memiliki 5 buah sampel setiap variannya, dan masing-masing pengujian diberi kode atau nama pada setiap sampelnya, untuk daya serapan air ditandai dengan kode SA, kuat tekan ditandai dengan KT. Pembuatan ini dimaksudkan untuk menghasilkan sampel penelitian yang akan di teliti. Mesin mix paving block seperti terlihat dalam Gambar 3.

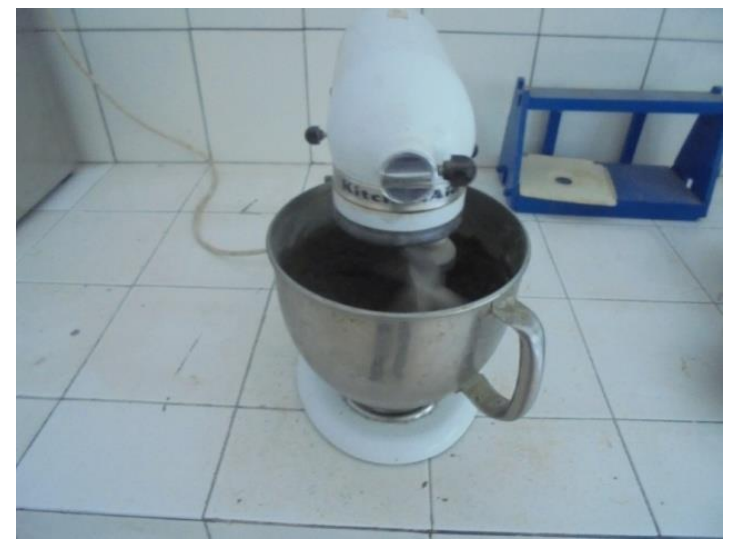

Gambar 3 Pengadukan benda uji (paving block kubus)

Setelah pengadukan paving block maka dilakukan langkah-langkah pembuatan paving block seperti dibawah ini:

1. Setelah pengadukan selesai, paving block di cetak dengan menggunakan cetakan kubus ukuran 8 × 8 x $11,6 \mathrm{~cm}$ dan slinder $15 \times 30 \mathrm{~cm}$.

2. Dilanjutkan dengan pengepresan dengan mesin kuat tekan dengan tekanan \pm 30 $\mathrm{KN}$.

3. Setelah pengepresan lalu benda uji dikeluarkan dari cetakan.

4. benda uji di letakkan pada permukanan yang rata dan tidak terkena sinar matahari langsung.

5. lalu pemberian nama pada sampel agar sampel tidak tertukar

6. didiamkan selama 24 jam sebelum dilanjutkan dengan perwatan (curing).

\subsection{Perawatan Benda Uji}

Setelah pencetakan selesai selanjutnya benda uji akan di lakukan perawatan dengan cara meletakkan benda uji di tempat yang teduh, terhindar dari tempat yang lembab, dan dilapisi dengan alas, hal ini berlanjut selama 24 jam setelah pencetakan. Kemudian dilakukan perendaman selama 28 hari, lalu dilakukan pengujian terhadap benda uji, yaitu pengujian daya serapan air, kuat tekan dan kuat tarik belah.

\subsection{Pengujian Paving Block}

Pengujian paving block mencakup pengujian daya serapan air, kuat tekan dan kuat tarik belah. 
a. Pengujian Daya Serapan Air Paving Block

Pengujian ini dilakukan untuk mengetahui jumlah air yang diserap oleh paving block yang telah direndam. Pelaksanaan pengujian serapan air dilakukan dengan metode berikut:

1) Setelah sampel berumur 28 hari perendaman, sampel dikeluarkan dari bak perendaman kemudian dikeringkan dengan cara mengelap permukaan

2) Kemudian benda uji ditimbang beratnya guna mengambil massa basah paving block

3) Selajutnya benda uji dikeringkan dengan oven dengan suhu $(110 \pm 5)^{\circ} \mathrm{C}$, selama 24 jam pengovenan.

4) Setelah pengovenan dan pendinginan benda uji di timbang lagi untuk berat kering paving block.

5) Perhitungan serapan air dapat diakukan dengan persamaan di bawah ini.

$$
W_{A}=\frac{M_{j}-M_{k}}{M_{k}} \times 100 \%
$$

Keterangan:

$W_{A}=$ Serapan air $(\mathrm{kg})$

$M_{k}=$ Berat paving block dalam keadaan kering $(\mathrm{kg})$

$M_{j}=$ Berat paving block setelah direndam didalam air $(\mathrm{kg})$

b. Pengujian Kuat Tekan Paving Block

Pengujian kuat tekan ini dilakukan untuk menentukan nilai kuat tekan pada paving block. Pengujian kuat tekan dilakukan pada saat paving block berumur 28 hari, dimana pengujian dilakukan dengan mesin uji tekan beton kapasitas $2000 \mathrm{KN}$. metode pelaksanaan pengujian kuat tekan yaitu:

1) Sampel dikeluarkan dari bak perendaman lalu dikeringkan menggunakan lap

2) Benda uji ditimbang beratnya

3) Lalu benda uji dimasukkan dalam penekan secara vertical

4) Mesin penguji dihidupkan dengan tekanan yang konstan hingga benda uji tidak sanggup lagi menahan beban dan mengalami retak

5) Benda uji dikeluarkan dari dalam mesin uji kuat tekan

6) Perhitungan dapat dilakukan dengan persamaan di bawah ini.

$$
f^{\prime} c=\frac{P_{\text {maks }}}{A}
$$

Keterangan:

$$
\begin{aligned}
& f^{\prime} \mathrm{C}=\text { Kuat tekan }(\mathrm{Mpa}) \\
& P_{\text {maks }}=\text { Beban maksimum }(\mathrm{N}) \\
& \text { A } \quad \text { Luas penampang benda uji }\left(\mathrm{mm}^{2}\right)
\end{aligned}
$$

\section{Hasil dan Pembahasan}

\subsection{Hasil Penelitian}

\subsubsection{Pengujian serapan air paving block}

Pengujian serapan air ini dilakukan untuk mengetahui jumlah air yang diserap oleh sampel (paving block), dimana setelah sampel berumur 28 hari perawatan (curing), sampel dikeluarkan dan dilap hingga kering permukaan, kemuadian ditimbang lalu dilakukan pengovenan dengan suhu $110^{\circ} \mathrm{C}$ untuk 
mendapatkan sampel kering oven kemudian sampel di keluarkan untuk didinginkan lalu di timbang beratnya.

Menurut Orchard (1979), berat jenis digunakan untuk menentukan volume yang diisi oleh agregat, berat jenis pada agregat pada akhirnya akan menentukan berat beton, sehingga secara langsung menentukan banyaknya campuran agregat dalam campuran beton. Menurut Mukhlis (2013), Hubungan berat jenis dengan serapan air agregat (water absorption) adalah, jika semakin tinggi nilai berat jenis agregat, maka semakin kecil nilai daya serap air agregat tersebut.

\subsubsection{Pengujian kuat tekan paving block}

Nilai kuat tekan adalah hasil dari perbandingan antara beban yang berkerja dengan luas penampang pada sampel (paving block). Walaupun terdapat tegangan tarik namun diasumsikan bahwa semua tegangan tekan didukung oleh beton tersebut. Pengujian kuat tekan dilakukan pada saat umur 24 jam, 3 hari, 7 hari, 28 hari dan 90 hari. Namun pada penelitian ini dilakukan pengujian pada saat paving block berumur 28 hari. Alat yang digunakan untuk melakukan pengujia ini adalah mesin uji kuat tekan.

\subsection{Pembahasan}

\subsubsection{Serapan air paving block}

Pada hasil pengujian serapan air dapat dilihat seberapa besar pengaruh tambahan serat kulit pinang pada paving block dengan berbagai variasi campuran serat. Hasil pengujian penyerapan air paving block dapat di lihat pada Tabel 3.

Tabel 3 Hasil pengujian penyerapan air paving block

\begin{tabular}{cccc}
\hline \hline No. & $\begin{array}{c}\text { CAMPURAN } \\
\text { SERAT (\%) }\end{array}$ & $\begin{array}{c}\text { UMUR PERAWATAN } \\
\text { (HARI) }\end{array}$ & $\begin{array}{c}\text { PENYERAPAN AIR } \\
\text { RATA-RATA (\%) }\end{array}$ \\
\hline \hline 1 & 0 & 28 & 9,57 \\
\hline 2 & 5 & 28 & 15,17 \\
\hline 3 & 10 & 28 & 15,56 \\
\hline 4 & 15 & 28 & 15,96 \\
\hline 5 & 20 & 28 & 16,65 \\
\hline \hline
\end{tabular}

Bentuk gambar dari serapan air rata-rata pada paving block dapat dilihat pada Gambar 4.

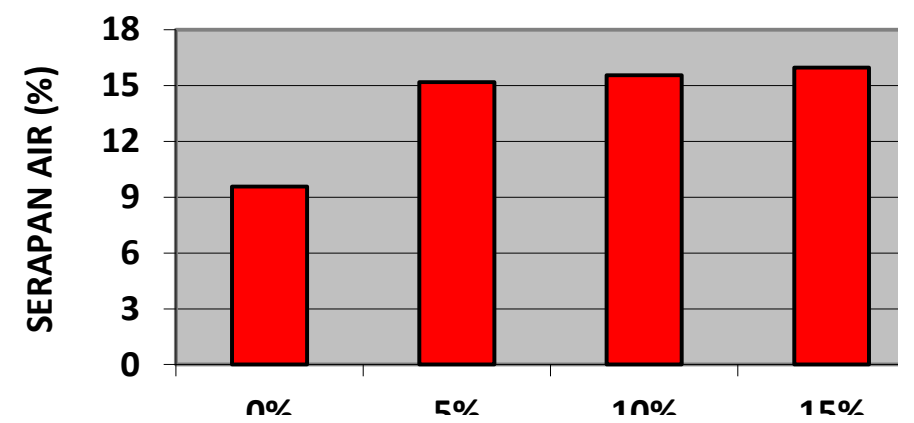

Gambar 4 Serapan air rata-rata pada paving block 
Dari Gambar 4 dapat dilihat bahwa penggunaan serat kulit pinang dengan variasi campuran serat dari volume pasir di peroleh serapan air rata-rata dalam penggunaan serat kulit pinang $(5 \%, 10 \%, 15 \%$, dan $20 \%)$ mengalami peningkatan secara berurut sebesar $9,57 \%, 15,17 \%, 15,56 \%, 15,96 \%$ dan $16,65 \%$. Hal ini terjadi karna sifat alami serat yang menyerap air, sehingga semakin banyak serat yang digunakan sebagai campuran, maka akan semakin tinggi daya serapan airnya. Hasil penelitian menunjukkan nilai rata-rata serapan air dengan variasi $5 \%, 10 \%, 15 \%$ dan $20 \%$ menunjukkan diatas 10\%. Berdasarkan SNI 03-06911996 penyerapan air rata-rata maksimal untuk paving block mutu D adalah $10 \%$.

\subsubsection{Kuat tekan paving block}

Pada hasil pengujian kuat tekan ini dapat dilihat bahwa penggunaan serat kulit pinang dengan variasi campuran serat $0 \%$ dari volume pasir di peroleh kuat tekan sebesar 8,83 Mpa, penggunaan serat kulit pinang dengan variasi campuran serat 5\% dari volume pasir di peroleh kuat tekan sebesar 7,44 Mpa, penggunaan serat kulit pinang dengan variasi campuran serat $10 \%$ dari pasir volume di peroleh kuat tekan sebesar 6,23 Mpa, penggunaan serat kulit pinang dengan variasi campuran serat $15 \%$ dari volume pasir di peroleh kuat tekan sebesar 5,13 Mpa, dan penggunaan serat kulit pinang dengan variasi campuran serat $20 \%$ dari volume pasir di peroleh kuat tekan sebesar 4,20 Mpa, nilai pengujian kaut tekan ini dapat dilihat seberapa besar pengaruh tambahan serat kulit pinang pada paving block dengan berbagai variasi campuran serat. Hasil pengujian kuat tekan paving block dapat diperlihatkan pada Tabel 4.

Tabel 4 Hasil pengujian kuat tekan paving block

\begin{tabular}{cccc}
\hline \hline No. & $\begin{array}{c}\text { CAMPURAN } \\
\text { SERAT }(\%)\end{array}$ & $\begin{array}{c}\text { UMUR PERAWATAN } \\
\text { (HARI) }\end{array}$ & $\begin{array}{c}\text { KUAT TEKAN } \\
\text { RATA-RATA (\%) }\end{array}$ \\
\hline \hline 1 & 0 & 28 & 8,83 \\
\hline 2 & 5 & 28 & 7,44 \\
\hline 3 & 10 & 28 & 6,23 \\
\hline 4 & 15 & 28 & 5,13 \\
\hline 5 & 20 & 28 & 4,20 \\
\hline \hline
\end{tabular}

Bentuk gambar dari nilai rata-rata kuat tekan pada paving block dapat dilihat pada Gambar 5.

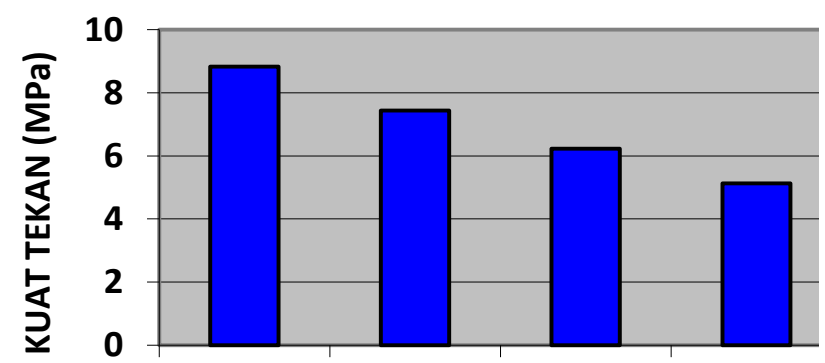

Gambar 5 Kuat tekan rata-rata pada paving block 
Dari Gambar 5 adanya penurunan grafik, hal ini disebabkan oleh bentuk dan struktur serat yang tidak keras dan tidak kaku, sehingga menyebabkan daya tekan menurun. Hasil penelitian ini menunjukkan nilai rata-rata dengan variasi 5\%,10\%, 15\% dan 20\% masih dibawah $10 \mathrm{MPa}$. Berdasarkan SNI 03-0691-1996 kuat tekan rata-rata untuk paving block mutu $\mathrm{D}$ adalah $10 \mathrm{MPa}$.

\section{Kesimpulan dan Saran}

\subsection{Kesimpulan}

Dari hasil penelitian didapatkan bahwa penggunaan serat kulit pinang meningkatkan serapan air. Hasil penelitian ini menunjukkan nilai rata-rata serapan air dengan variasi $5 \%, 10 \%, 15 \%$ dan $20 \%$ mengalami peningkatan secara berurut sebesar $9,57 \%, 15,17 \%, 15,56 \%, 15,96 \%$ dan 16,65\%. Hal ini terjadi karna sifat alami serat yang menyerap air, sehingga semakin banyak serat yang digunakan sebagai campuran, maka akan semakin tinggi daya serapan airnya. Kuat tekan paving block mengalami penurunan yang siqnifikan. Penurunan ini sesuai dengan kenaikan serapan air. Kuat tekan paving block dengan nilai rata-rata variasi $5 \%, 10 \%, 15 \%$ dan 20\% masih dibawah $10 \mathrm{MPa}$. Ini membuktikan bahwa sistem kerja serat kulit pinang tidak dapat digunakan dalam memperbaiki sifat-sifat mekanik paving block dalam perkembangan teknologi beton.

\subsection{Saran}

Penelitian ini hanya dilakukan dengan penambahan variasi banyaknya serat $0 \%, 5 \%, 10 \%, 15 \%$ dan $20 \%$. Untuk memperbaiki sifat mekanik paving block menjadi lebih baik maka perlu adanya penelitian lebih komprehensif terhadap penelitian selanjutnya tentang pemanfaatan jenis limbah serat lain nya misalnya serat tandan kosong kelapa sawit, serat ijuk atau sejenis lainya. Pengunaan serat dapat digunakan sebagai asumsi kuat tekan dalam menahan gesekan dan retak pada paving block. Agar kedepan nya didapat kajian lebih mendalam tentang perilaku serapan air dan kuat tekan pada paving block.

\section{Daftar Kepustakaan}

Adibroto, F., 2014. Pengaruh Penambahan Berbagai Jenis Serat Pada Kuat Tekan Paving Block. Jurnal Rekayasa Sipil, Padang.

Badan Standar Nasional, 1982. ASTM C 33-1982 Analisis Saringan Agregat Halus Dan Kasar. Jakarta.

Badan Standar Nasional, 1990. SK SNI T-04-1990-F Tata Cara Pemasangan Blok Beton Terkunci Untuk Permukaan Jalan Bagian 1.3 Pengertian.

Badan Standar Nasional, 1996. SNI 03-0691-1996 Bata Beton (Paving Block)

Bagian 3: Definisi, bagian 5: Syarat mutu, bagian 5.3: Sifat fisika.

Mulyono, Tri., 2004, Teknologi Beton. Penerbit Andi, Yogyakarta.

Mukhlis, 2013. Water Absorption. Palembang.

Orchard, 1979. Konsep Paving Block Ramah Lingkungan. Yogyakarta.

Saputro, Danu., 2007. Rekayasa Lingkungan. Bandung.

Wintoko, 2012. Sukses Wirausaha Paving Block. Surabaya.

Copyright (c) Mul Muliadi Adi, wesli wesli, aulia rahman aulia

Pengaruh Limbah Serat Kulit Pinang Terhadap Serapan Air Dan Kuat Tekan Pada

Paving Block - Muliadi, Wesli, Aulia Rahman 